\title{
DYNAMICS OF STUDENTS' FITNESS LEVEL WHILE DIFFERENTIATING PHYSICAL EDUCATION CLASSES IN ACCORDANCE WITH THEIR HEALTH AND NOSOLOGY OF DISEASES
}

DOI: 10.36740/WLek202103214

\author{
Grygoriy P. Griban' ${ }^{1}$, Olena T. Kuznietsova ${ }^{2}$, Natalia A. Lyakhova ${ }^{3}$, Volodymyr M. Prystynskyi ${ }^{4}$, Dmytro G. Oleniev ${ }^{5}$, \\ Olena V. Otravenko ${ }^{6}$, Olena 0. Pantus ${ }^{7}$ \\ 'ZHYTOMYR IVAN FRANKO STATE UNIVERSITY, ZHYTOMYR, UKRAINE \\ "EDUCATIONAL ESTABLISHMENT “POLESSKY STATE UNIVERSITY", PINSK, REPUBLIC OF BELARUS \\ 3UKRAINIAN MEDICAL STOMATOLOGICAL ACADEMY, POLTAVA, UKRAINE \\ ${ }^{4}$ DONBAS STATE PEDAGOGICAL UNIVERSITY, SLOV'YANSK, UKRAINE \\ 'THE NATIONAL DEFENSE UNIVERSITY OF UKRAINE, KYIV, UKRAINE \\ ¿LUHANSK TARAS SHEVCHENKO NATIONAL UNIVERSITY, LUHANSK, UKRAINE \\ ${ }^{7}$ POLISSIA NATIONAL UNIVERSITY, ZHYTOMYR, UKRAINE
}

\begin{abstract}
The aim: Is to study the dynamics of students' physical fitness level while differentiating physical education classes in accordance with their somatic health and nosology of diseases. Materials and methods: The paper presents the results of a study of the dynamics of the physical fitness indicators of students in the process of physical education. The study involved 660 students between the ages of 17 and 25. Testing of students' physical fitness was performed using the method of control measurements. Research methods included the theoretical analysis and generalization of scientific and methodical literature, pedagogical observations, testing, pedagogical experiment, and the methods of mathematical statistics.

Results: At the end of the experiment, the students of the experimental groups (both male and female) showed authentically $(p<0.05-0.001)$ better indicators of the control tests than the students of the control groups.

Conclusions: It was established that the introduction of the original program of differentiating classes in accordance with the level of students' somatic health and nosology of diseases into the process of physical education has a positive effect on their physical fitness level. This will help to improve their learning and future professional activities.
\end{abstract}

KEY WORDS: students, differentiating physical education classes, health, physical fitness

$\overline{\text { Wiad Lek. 2021;74(3 p.II):641-646 }}$

\section{INTRODUCTION}

Physical fitness is an important indicator of the health and physical education of students, which ensures their readiness to perform the physical activities provided by the curriculum at higher education institutions (HEI) [1, $2,3]$. Physical fitness characterizes the level of physical qualities development, which was achieved in the process of physical education $[4,5,6]$. The physical fitness of students is related to the level of physical health. It can be argued that a student who has a high level of physical health also has a high level of physical fitness. Therefore, the results of motor tests of the students with a "safe" level of physical health are benchmarking for the development of motor skills of young people with lower levels of health. Physical fitness of students should be focused on improving health and only indirectly on the results of motor tests $[7,8]$. The introduction of control tests significantly activates students, changes their attitude to the educational process $[9,10]$.
The issue of the differentiating physical education classes has been studied in the works of scientists [11, 12], however, given the current state of health and physical fitness of school and university students, it still remains relevant.

\section{THE AIM}

The aim is to study the dynamics of students' physical fitness level while differentiating physical education classes in accordance with their somatic health and nosology of diseases.

\section{MATERIALS AND METHODS}

The study was conducted at Polissia National University (PNU), Zhytomyr Ivan Franko State University (ZSU) (Ukraine) and Polessky State University (PSU) (Republic of Belarus). To analyze the state of students' physical fitness, we organized an initial experiment, which involved 388 students (142 students from PNU, 127 students from ZSU, 
Table I. The physical fitness state of male students $(X \pm m)$

\begin{tabular}{ccccc}
\hline Types of tests & \multicolumn{3}{c}{ The year of study } \\
\cline { 2 - 5 } & 1st & 2nd & 3rd & $16.79 \pm 0.99$ \\
\hline 100 m run (s) & $16.64 \pm 0.75$ & $16.65 \pm 1.09$ & $16.37 \pm 0.62$ & $200.31 \pm 14.23$ \\
\hline Standing long jumps (cm) & $204.31 \pm 12.37$ & $212.41 \pm 14.52$ & $205.30 \pm 15.23$ & $22.20 \pm 5.12$ \\
\hline Push-ups (reps) & $24.63 \pm 5.27$ & $25.52 \pm 4.26$ & $24.09 \pm 6.48$ & $09.70 \pm 3.15$ \\
\hline Pull-ups (reps) & $11.50 \pm 1.64$ & $11.49 \pm 3.03$ & $09.23 \pm 3.46$ & $24.48 \pm 3.18$ \\
\hline Sit-ups in 1 min (reps) & $25.41 \pm 3.86$ & $25.77 \pm 1.80$ & $24.58 \pm 3.49$ & $6.87 \pm 0.42$ \\
\hline Single-leg squats (reps) & $6.44 \pm 0.58$ & $6.87 \pm 0.49$ & $6.54 \pm 0.23$ & $10.30 \pm 3.09$ \\
\hline Bending forward in a sitting position $(\mathrm{cm})$ & $12.54 \pm 1.69$ & $11.52 \pm 3.03$ & $09.21 \pm 5.43$ & \\
\hline
\end{tabular}

Table II. The physical fitness state of female students $(X \pm m)$

\begin{tabular}{ccccc}
\hline Types of tests & \multicolumn{4}{c}{ The year of study } \\
\cline { 2 - 5 } & 1st & 2nd & 3rd & 4th \\
\hline 100 m run (s) & $18.31 \pm 0.87$ & $18.55 \pm 0.79$ & $18.77 \pm 0.72$ & $18.75 \pm 0.98$ \\
\hline Push-ups (on the knees) (reps) & $21.34 \pm 1.52$ & $20.81 \pm 1.98$ & $20.09 \pm 2.28$ & $19.56 \pm 2.92$ \\
\hline Sit-ups in 1 min (reps) & $23.73 \pm 6.12$ & $28.07 \pm 2.93$ & $24.66 \pm 3.11$ & $23.78 \pm 4.96$ \\
\hline Bending forward in a sitting position (cm) & $10.88 \pm 3.07$ & $11.61 \pm 1.92$ & $11.21 \pm 2.17$ & $10.12 \pm 2.10$ \\
\hline Arch hold (reps) & $19.29 \pm 1.29$ & $18.46 \pm 1.47$ & $17.98 \pm 1.83$ & $17.21 \pm 2.83$ \\
\hline Lunges (reps) & $14.80 \pm 0.42$ & $14.47 \pm 0.63$ & $14.29 \pm 0.42$ & $14.03 \pm 1.94$ \\
\hline
\end{tabular}

119 students from PSU): 175 male and 213 female students of the 1 st- 4 th years of study ( 1 st year $n=88 ; 2$ nd year $n=141$; 3 rd year $n=93 ; 4$ th year $n=66$ ). To substantiate the authors' program of differentiating physical education classes, 2 experimental $(n=139)$ and 2 control $(n=133)$ groups of the students of the 1st-2nd year (male and female) were formed. The experimental group EGm included 60 male students, and the EGf group - 79 female students; the control group CGm - 52 male students, CGf - 81 female students. The students of experimental groups were engaged in the sectional form of physical education according to the original program, according to which the means of physical education and physical activity were differentiated depending on the level of physical health, disease nosology, doctor's indications, and the requirements of future professional activity. The students of control groups attended traditional physical education classes at HEI. The number of hours devoted to physical education per week in the experimental and control groups was the same and accounted for 4 hours.

The students' physical fitness level was assessed using control tests. The tests were applied to evaluate power qualities: 1) standing long jumps (males); 2) push-ups (males - lying on the floor, females - standing on the knees); 3) pull-ups on the crossbar (males); 4) sit-ups in 1 min; 5) single-leg squats (males); 6) the arch hold (females); 7) lunges (females). In order to assess the speed, a $100 \mathrm{~m}$ race with a sprint start was used. Flexibility was assessed by the exercise of bending forward in a sitting position. The following tests were used in the experimental groups to monitor the development of professionally significant motor skills: 1) the Cooper test (run-walk within 12 min- utes) - to assess overall endurance; 2) the Flamingo Balance Test - to control coordination abilities.

The research methods included theoretical analysis and generalization of scientific and methodical literature, pedagogical observations, testing, pedagogical experiment, and the methods of mathematical statistics.

\section{RESULTS}

The state of physical fitness of the students of the 1st - 4th years can be considered satisfactory in general (Tables I, II). The level of physical fitness of the female students of the 1 st -2 nd years was better than that of male students. The students of the $3 r d-4$ th years were defined to have a tendency of changing results.

The satisfactory indicators of the students' physical fitness indicated not only the actual state of their physical fitness but also the shortcomings of the curriculum. The increase in the number of students with disabilities, the hard disease course, and the disease development for younger people were the reasons to lower the criteria for assessing some physical qualities. The control over the development of such important human qualities as general endurance and coordination skills was eliminated because the students were given an alternative choice of 4 test exercises in each semester out of 10 common and 8 variable control exercises. This implied that only the most effective type of control tests for each student was evaluated.

The analysis of the study results shows that a very low level of physical fitness was shown by $27.27 \%$ of first-year students, $20.83 \%$ of second-year students, $33.33 \%$ of third-year students, and $25.00 \%$ of fourth-year students. 
Table III. The dynamics of the male students' physical fitness indicators after introducing the original program into the educational process $(X \pm m)$

\begin{tabular}{|c|c|c|c|c|c|c|}
\hline \multirow[t]{2}{*}{ Tests } & \multirow[t]{2}{*}{ Groups } & \multirow[t]{2}{*}{ Initial data } & \multirow[t]{2}{*}{ Final data } & \multirow[t]{2}{*}{ Changes } & \multicolumn{2}{|c|}{$\begin{array}{l}\text { Significance of } \\
\text { differences }\end{array}$} \\
\hline & & & & & $\mathbf{t}$ & $\mathbf{p}$ \\
\hline \multirow{4}{*}{$\begin{array}{l}\text { Cooper test - run-walk within } \\
12 \text { minutes }(\mathrm{m})\end{array}$} & EGm1 & $1278.46 \pm 59.16$ & $1777.34 \pm 68.58$ & 498.88 & 2.34 & $<0.05$ \\
\hline & CGm1 & $1291.58 \pm 63.14$ & $1512.07 \pm 66.72$ & 220.49 & 1.68 & $>0.05$ \\
\hline & $\mathrm{EGm} 2$ & $1421.31 \pm 67.78$ & $2039.54 \pm 78.63$ & 618.23 & 5.06 & $<0.001$ \\
\hline & CGm2 & $1413.83 \pm 69.13$ & $1799.25 \pm 72.34$ & 385.42 & 2.19 & $<0.05$ \\
\hline \multirow{4}{*}{$100 \mathrm{~m}$ run (s) } & EGm1 & $17.91 \pm 1.11$ & $16.21 \pm 0.97$ & 1.70 & 2.89 & $<0.01$ \\
\hline & CGm1 & $17.74 \pm 0.93$ & $17.19 \pm 1.05$ & 0.55 & 1.94 & $>0.05$ \\
\hline & $\mathrm{EGm} 2$ & $16.93 \pm 1.08$ & $15.46 \pm 1.13$ & 1.47 & 2.47 & $<0.05$ \\
\hline & CGm2 & $16.42 \pm 0.86$ & $16.14 \pm 1.22$ & 0.28 & 1.63 & $>0.05$ \\
\hline \multirow{4}{*}{ Standing long jumps (cm) } & EGm1 & $178.72 \pm 1.84$ & $199.14 \pm 2.16$ & 20.42 & 2.92 & $<0.01$ \\
\hline & CGm1 & $181.40 \pm 1.67$ & $187.43 \pm 1.77$ & 6.03 & 1.83 & $>0.05$ \\
\hline & $\mathrm{EGm} 2$ & $186.63 \pm 1.92$ & $201.16 \pm 2.14$ & 14.53 & 2.51 & $<0.05$ \\
\hline & CGm2 & $187.85 \pm 1.87$ & $189.64 \pm 1.65$ & 1.79 & 1.49 & $>0.05$ \\
\hline \multirow{4}{*}{ Pull-ups (reps) } & EGm1 & $4.24 \pm 0.64$ & $6.98 \pm 0.66$ & 2.74 & 3.82 & $<0.001$ \\
\hline & CGm1 & $4.71 \pm 0.57$ & $4.92 \pm 0.54$ & 0.21 & 1.64 & $>0.05$ \\
\hline & EGm2 & $5.62 \pm 0.77$ & $8.29 \pm 0.72$ & 2.67 & 3.23 & $<0.01$ \\
\hline & CGm2 & $5.80 \pm 0.82$ & $5.95 \pm 0.76$ & 0.15 & 1.57 & $>0.05$ \\
\hline \multirow{4}{*}{ Sit-ups in $30 \mathrm{~s}$ (reps) } & EGm1 & $11.36 \pm 0.95$ & $21.63 \pm 1.67$ & 10.27 & 4.23 & $<0.001$ \\
\hline & CGm1 & $12.14 \pm 0.91$ & $14.21 \pm 0.99$ & 2.07 & 1.62 & $>0.05$ \\
\hline & EGm2 & $13.62 \pm 0.85$ & $23.87 \pm 1.48$ & 10.25 & 4.17 & $<0.001$ \\
\hline & CGm2 & $13.91 \pm 0.79$ & $16.12 \pm 0.86$ & 2.21 & 1.72 & $>0.05$ \\
\hline \multirow{4}{*}{ Flamingo Balance Test (s) } & EGm1 & $7.95 \pm 0.95$ & $11.54 \pm 1.16$ & 3.59 & 2.96 & $<0.01$ \\
\hline & CGm1 & $8.15 \pm 0,66$ & $8.59 \pm 0.84$ & 0.44 & 1.85 & $>0.05$ \\
\hline & EGm2 & $8.27 \pm 0.72$ & $13.36 \pm 1.32$ & 5.09 & 4.52 & $<0.001$ \\
\hline & CGm2 & $8.33 \pm 0.63$ & $9.41 \pm 0.81$ & 1.08 & 1.83 & $>0.05$ \\
\hline \multirow{4}{*}{$\begin{array}{l}\text { Bending forward standing on } \\
\text { a bench }(\mathrm{cm})\end{array}$} & EGm1 & $11.14 \pm 0.43$ & $13.77 \pm 0.87$ & 2.63 & 2.56 & $<0.05$ \\
\hline & CGm1 & $10.25 \pm 0.67$ & $10.94 \pm 0.71$ & 0.69 & 1.92 & $>0.05$ \\
\hline & EGm2 & $10.02 \pm 0.56$ & $14.52 \pm 0.86$ & 4.50 & 3.24 & $<0.01$ \\
\hline & CGm2 & $11.05 \pm 0.62$ & $11.58 \pm 0.69$ & 0.53 & 1.81 & $>0.05$ \\
\hline \multirow{4}{*}{ Single-leg squats (reps) } & EGm1 & $5.68 \pm 0.49$ & $8.67 \pm 0.69$ & 2.99 & 2.98 & $<0.01$ \\
\hline & CGm1 & $5.45 \pm 0.56$ & $5.94 \pm 0.60$ & 0.49 & 1.79 & $>0.05$ \\
\hline & $\mathrm{EGm} 2$ & $6.13 \pm 0.65$ & $9.98 \pm 0.75$ & 3.85 & 4.07 & $<0.001$ \\
\hline & CGm2 & $5.24 \pm 0.51$ & $6.29 \pm 0.58$ & 1.05 & 1.96 & $>0.05$ \\
\hline
\end{tabular}

The students showed the best results during the exercise of standing long jumps. The largest number of female students who participated in the testing was observed among first- and second-year students depending on the type of tests, the smallest number - in all tests among fourth-year students. There was a noticeable tendency to decrease in the number of test participants from year to year for both males and females. Depending on the type of test, the percentage of the total number of students ranged from $18.69 \%-71.96 \%$ (first year), $42.97 \%-74.38 \%$ (second year), $26.21 \%-40.00 \%$ (third year), $20.00 \%-40.00 \%$ (fourth year).

The analysis of the results of physical fitness shows that, first, fitness standards are not suitable for most students with disabilities, which necessitates a revision of the criteria for assessing physical fitness, taking into account individual capabilities, physical condition, and future professional requirements. Secondly, an urgent requirement today is the introduction of a differentiated approach when planning physical activity, taking into account the level of physical health of students. 


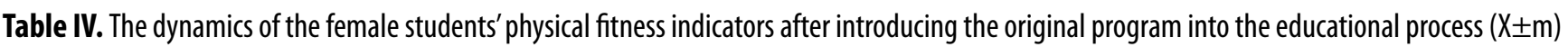

\begin{tabular}{|c|c|c|c|c|c|c|}
\hline \multirow[t]{2}{*}{ Tests } & \multirow[t]{2}{*}{ Groups } & \multirow[t]{2}{*}{ Initial data } & \multirow[t]{2}{*}{ Final data } & \multirow[t]{2}{*}{ Changes } & \multicolumn{2}{|c|}{$\begin{array}{l}\text { Significance of } \\
\text { differences }\end{array}$} \\
\hline & & & & & $\mathbf{t}$ & $\mathbf{p}$ \\
\hline \multirow{4}{*}{$\begin{array}{l}\text { Cooper test - run-walk within } 12 \\
\text { minutes }(\mathrm{m})\end{array}$} & EGf1 & $1128.42 \pm 56.14$ & $1534.51 \pm 57.38$ & 406.09 & 2.38 & $<0.05$ \\
\hline & CGf1 & $1131.53 \pm 56.31$ & $1366.49 \pm 58,37$ & 234.96 & 1.64 & $>0.05$ \\
\hline & EGf2 & $1250.28 \pm 57.86$ & $1798.74 \pm 61.26$ & 548.46 & 2.47 & $<0.05$ \\
\hline & CGf2 & $1259.89 \pm 58.05$ & $1484.63 \pm 59.23$ & 224.74 & 1.53 & $>0.05$ \\
\hline \multirow{4}{*}{100 m run (s) } & EGf1 & $20.53 \pm 0.83$ & $18.96 \pm 0.68$ & 1.57 & 2.31 & $<0.05$ \\
\hline & CGf1 & $19.34 \pm 0.90$ & $19.04 \pm 0.96$ & 0.30 & 1.73 & $>0.05$ \\
\hline & EGf2 & $19.07 \pm 0.89$ & $18.72 \pm 0.86$ & 0.35 & 1.79 & $>0.05$ \\
\hline & CGf2 & $20.92 \pm 0.96$ & $20.47 \pm 0.91$ & 0.45 & 1.84 & $>0.05$ \\
\hline \multirow{4}{*}{ Standing long jumps (cm) } & EGf1 & $143.74 \pm 2.64$ & $158.67 \pm 2.65$ & 14.93 & 2.45 & $<0.05$ \\
\hline & CGf1 & $148.91 \pm 2.14$ & $149.32 \pm 2.53$ & 0.41 & 1.34 & $>0.05$ \\
\hline & EGf2 & $149.36 \pm 2.38$ & $161.17 \pm 2.49$ & 11.81 & 2.32 & $<0.05$ \\
\hline & CGf2 & $152.29 \pm 2.71$ & $153.65 \pm 2.68$ & 1.36 & 1.89 & $>0.05$ \\
\hline \multirow{4}{*}{ Push-ups on the knees (reps) } & EGf1 & $21.34 \pm 1.45$ & $26.67 \pm 1.58$ & 5.33 & 2.65 & $<0.05$ \\
\hline & CGf1 & $20.03 \pm 1.53$ & $21.45 \pm 1.75$ & 1.42 & 1.59 & $>0.05$ \\
\hline & EGf2 & $22.64 \pm 1.67$ & $27.93 \pm 1.84$ & 5.29 & 2.48 & $<0.05$ \\
\hline & CGf2 & $21.78 \pm 1.49$ & $22.13 \pm 1.52$ & 0.35 & 1.30 & $>0.05$ \\
\hline \multirow{4}{*}{ Sit-ups in $30 \mathrm{~s}$ (reps) } & EGf1 & $8.93 \pm 0.64$ & $18.03 \pm 0.77$ & 9.10 & 4.28 & $<0.001$ \\
\hline & CGf1 & $9.44 \pm 0.78$ & $11.21 \pm 0.69$ & 1.77 & 1.87 & $>0.05$ \\
\hline & EGf2 & $10.72 \pm 0.83$ & $19.68 \pm 0.91$ & 8.96 & 4.19 & $<0.001$ \\
\hline & CGf2 & $11.60 \pm 0.72$ & $13.24 \pm 0.82$ & 1.64 & 1.72 & $>0.05$ \\
\hline \multirow{4}{*}{ Flamingo Balance Test (s) } & EGf1 & $7.95 \pm 0.95$ & $12.65 \pm 0.86$ & 4.70 & 2.87 & $<0.01$ \\
\hline & CGf1 & $8.18 \pm 0.66$ & $9.14 \pm 0.74$ & 0.96 & 1.34 & $>0.05$ \\
\hline & $\mathrm{EGf2}$ & $7.80 \pm 0.72$ & $13.53 \pm 0.93$ & 5.73 & 2.98 & $<0.01$ \\
\hline & CGf2 & $8.13 \pm 0.43$ & $9.67 \pm 0.61$ & 1.54 & 1.57 & $>0.05$ \\
\hline \multirow{4}{*}{ Bending forward (cm) } & EGf1 & $10.10 \pm 0.69$ & $13.75 \pm 0.86$ & 3.65 & 2.57 & $<0.05$ \\
\hline & CGf1 & $10.50 \pm 0.73$ & $10.89 \pm 0.74$ & 0.39 & 1.24 & $>0.05$ \\
\hline & EGf2 & $11.07 \pm 0.79$ & $14.36 \pm 0.97$ & 3.29 & 2.43 & $<0.05$ \\
\hline & CGf2 & $10.45 \pm 0.81$ & $11.25 \pm 0.67$ & 0.80 & 1.46 & $>0.05$ \\
\hline \multirow{4}{*}{ Arch hold (reps) } & EGf1 & $14.23 \pm 0.93$ & $18.83 \pm 1.23$ & 4.60 & 2.67 & $<0.05$ \\
\hline & CGf1 & $15.02 \pm 1.09$ & $16.22 \pm 1.11$ & 1.20 & 1.53 & $>0.05$ \\
\hline & EGf2 & $16.13 \pm 1.03$ & $21.43 \pm 1.27$ & 5.30 & 2.96 & $<0.01$ \\
\hline & CGf2 & $17.86 \pm 1.12$ & $18.99 \pm 1.18$ & 1.13 & 1.40 & $>0.05$ \\
\hline \multirow{4}{*}{ Lunges (reps) } & EGf1 & $12.34 \pm 0.94$ & $16.43 \pm 1.04$ & 4.09 & 2.52 & $<0.05$ \\
\hline & CGf1 & $14.17 \pm 0.98$ & $15.13 \pm 0.99$ & 0.96 & 1.35 & $>0.05$ \\
\hline & EGf2 & $13.56 \pm 0.87$ & $18.74 \pm 1.17$ & 5.18 & 2.93 & $<0.01$ \\
\hline & CGf2 & $14.63 \pm 0.93$ & $15.24 \pm 0.96$ & 0.61 & 1.42 & $>0.05$ \\
\hline
\end{tabular}

In order to ensure the physical education efficiency of the students of HEI, we developed an original program of differentiating physical education classes for students, which takes into account their level of physical health and disease nosology.

There are means of physical education provided that meet the interests, needs, and individual capabilities of students. In order to develop motor skills, we used physical exercises, which are basic in the curriculum: to develop general endurance - health walking and running, swimming, the elements of rhythmic gymnastics, dance, and step aerobics; to develop speed - running, swimming, sports games; to develop strength - exercises on gym-machines, with one's own weight, additional weights; to develop dex- 
terity - moving games and the elements of sports games, shuttle running, and relay races; to develop flexibility - the elements of rhythmic gymnastics, aerobics, fitness, yoga.

The following tools were used in classes with students with disabilities: with the students of group A (with diseases of the musculoskeletal system): exercises of classical, dance and step aerobics, fitness, yoga, pilates, sports games; with the students of group B (with diseases of the cardiorespiratory system): healthy running, walking, general development exercises, the elements of classical aerobics, yoga, active games, the elements of respiratory gymnastics and autogenic training; with the students of group $\mathrm{C}$ (with diseases of the visual organs, kidneys, and other internal organs): healthy running, walking, general developmental exercises, moving games, dance aerobics, exercises on cardio gym-machines, fitness, yoga, stretching, breathing exercises.

The analysis of the students' physical fitness indicators, obtained in the process of formative pedagogical experiment, convincingly proved the high efficiency of the original program. In all eight tests on physical fitness, male students of the experimental groups significantly improved their performance (Table III).

There were significant changes in the results in the experimental groups. The most significant results were demonstrated by the EGm2 students in the Cooper test, sit-ups in $30 \mathrm{~s}$, Flamingo Balance Test, single-leg squats $(\mathrm{p}<0.001)$; the EGm1 students - in pull-ups $(\mathrm{p}<0.001)$. The results of the experimental groups were also significantly improved in other tests $(\mathrm{p}<0.05 ; \mathrm{p}<0.01)$. In the control groups, males improved the results in all tests, but the average indicators were significantly lower $(\mathrm{p}>0.05)$. It should be noted that in EG1, CG1, both in the groups of males and females, there was a decrease in the number of subjects at the end of the experiment. Females from the experimental groups also significantly improved performance in all fitness tests, except for the results of EGf2 in the $100 \mathrm{~m}$ run. The best results in both EGf1 and EGf2 were achieved in sit-ups in $30 \mathrm{~s}(\mathrm{p}<0.001)$. The results in the Flamingo Balance Test also increased substantially $(\mathrm{p}<0.01)$. In the control groups, females improved the results in all tests, but the average values were lower than the level of reliability $(p>0.05)$. In general, the performance of the female students of the control groups was significantly lower (Table IV).

This generally characterizes the increase in reserve capacity of the students' motor systems and reflects the efficiency of the presented original program and organizational approaches providing physical education.

\section{DISCUSSION}

The analysis of the students' health in the process of physical education and the dynamics of their physical fitness indicators during different years of study, showed that the quantitative composition of students belonging to a particular level of physical fitness, differs between authors, and, in general, it characterizes the low state of the physical fitness of students in Ukraine, especially females $[13,14]$.
It was proved that the most common diseases among firstyear students of HEI are the diseases of the cardiovascular, digestive, and musculoskeletal systems. Some researchers propose to differentiate students on the nosological principle of diseases or combining several diseases $[8,11]$. However, even in a subgroup with the same diagnoses, there are students with different physical fitness levels and general physical performance, which leads to inconsistency of activities with the functional capabilities. At the same time, many students have not only one but two or more diseases, which also creates difficulties in attributing them to a certain nosological subgroup. In practice, there are also organizational problems in conducting classes on the nosological principle. There is an approach to the individualization of the students' physical training based on the types of the physique, constitutional identification, including a special medical group. The problem of choosing the principles of forming groups of students with disabilities is solved by the writing team. There are six main approaches to forming groups distinguished: on a nosological basis; taking into account the level of physical fitness; based on the functional abilities; according to the contraindications to physical activity; based on an individual differentiated approach; paying attention to the gender. At the same time, scientists agree with other experts and recognize the most acceptable principle of forming groups is based on nosology.

\section{CONCLUSIONS}

1. The level of physical fitness of first-year students was assessed as "low" or "below the medium". A very low level of physical fitness was demonstrated by $27.27 \%$ of the first-year male students, $20.83 \%$ of the second-year male students, $33.33 \%$ of the male third-year students, and $25.00 \%$ of the male fourth-year students. Besides, $14.89 \%$ of the first-year female students, $13.21 \%$ of the second-year female students, $15.00 \%$ of the third-year female students, $18.25 \%$ of the fourth-year female students did not get to the assessment scale.

2. It was found that there was not significant difference between the indicators physical fitness and health of students of Ukraine and the Republic of Belarus ( $p>0.05$ ), which indicates that Belarusian students have problems similar to Ukrainian students in the system of physical education in the HEI.

3. The introduction of the original program of differentiating physical education classes in the students' physical education process, taking into account their level of physical health, nosology of the disease, the doctor's instructions had a positive effect on the students' physical fitness level. The largest increase in the indicators of physical fitness of female students was recorded in the following control tests: sit-ups $(\mathrm{p}<0.001)$; Flamingo Balance Test $(\mathrm{p}<0.01)$; the arch hold $(\mathrm{p}<0.01)$; lunges $(\mathrm{p}<0.01)$. For the male students these were sit-ups $(\mathrm{p}<0.001)$; Flamingo Balance Test $(\mathrm{p}<0.001)$; single-leg squats $(\mathrm{p}<0.001)$; pull-ups $(\mathrm{p}<0.001)$; standing long jumps $(\mathrm{p}<0.01)$; the $100 \mathrm{~m}$ run $(\mathrm{p}<0.01)$; the Cooper test $(\mathrm{p}<0.05)$. 


\section{REFERENCES}

1. Griban G., Lyakhova N., Tymoshenko 0. et al. Current state of students' health and its improvement in the process of physical education. Wiad. Lek. 2020; 73(7): 1438-1447. doi: 10.36740/WLek202007124.

2. Prontenko K., Griban G., Dovgan N. et al. Students' health and its interrelation with physical fitness level. Sport Mont. 2019; 17(3): 41-46. doi 10.26773/smj.191018.

3. Mozolev 0., Bloshchynsky I., Alieksieiev 0. et al. Influence of modern fitness technologies on the state of health and development of motor abilities of 17-19-year-old female students. Journal of Physical Education and Sport. 2019; 19(3): 917-924. doi:10.7752/jpes. 2019.s3132.

4. Prontenko K., Bloshchynskyi I., Griban, G. et al. Formation of readiness of future physical culture teachers for professional activity. Universal Journal of Educational Research. 2019; 7(9): 1860-1868. doi: 10.13189/ ujer.2019.070903.

5. Griban G., Yavorska T., Tkachenko P. et al. Motor activity as the basis of a healthy lifestyle of student youth. Wiad. Lek. 2020; 73(6): 1199-1206. doi: 10.36740/WLek202006123.

6. Mozolev 0., Halus 0., Bloshchynskyi I. et al. Human resources management of educational development in sphere of physical culture and sports in Ukraine: comparative analysis (1992-2016). Journal of Physical Education and Sport. 2019; 19(1): 185-192. doi:10.7752/ jpes.2019.s1028.

7. Griban G., Kobernyk 0., Terentieva N. et al. Formation of health and fitness competencies of students in the process of physical education. Sport Mont. 2020; 18 (3): 73-78. doi: 10.26773/smj.201008.

8. Prysiazhniuk S., Tolubko V., Oleniev D. et al. The influence of physical activities on biological age parameters of the first-year female students from the special medical department. Journal of Physical Education and Sport. 2018; 18(2): 561-564. doi:10.7752/jpes.2018.02081.

9. Zhamardiy V., Shkola 0., Okhrimenko I. et al. Checking of the methodical system efficiency of fitness technologies application in students' physical education. Wiad Lek. 2020; 73 (2):332-341. doi: 10.36740/ WLek202002125.

10. Prontenko K., Griban G., Aloshyna A. et al. The physical development and functional state as the important components of the students' health. Wiad. Lek. 2019; 72(12a):2348-2353. doi: 10.36740/WLek201912115.

11. Arefiev V., Tymoshenko 0., Malechko T. et al. Methodology of differentiation of health-improving classes in physical education for primary school students. International Journal of Applied Exercise Physiology. 2020; 9(7): 134-143.

12. Griban G., Tymoshenko 0., Arefiev V. et al. The role of physical education in improving the health status of students of special medical groups. Wiad. Lek. 2020; 73 (3): 534-540. doi: 10.36740/WLek202003125.
13. Prontenko K., Griban G., Bloshchynskyi I. et al. Improvement of students' morpho-functional development and health in the process of sport-oriented physical education. Wiad Lek. 2020; 73(1): 161-168. doi: 10.36740/WLek202001131.

14. Makarov S., Stoyan N., Serheta I. et al. Peculiarities of the interaction of the indicators of psychophysiological adaptation of modern students in the context of the effective monitoring of individual health of young women and young men. Wiad. Lek. 2019; 72 (5a): 1053-1058.

The article was carried out according to the plan of the research work of Zhytomyr Ivan Franko State University for 2014-2024 on the theme of "Theoretical and methodological bases of improving the educational process of physical education at higher educational institutions» (state registration number 0114U003978).

\section{ORCID and contributionship:}

Grygoriy P. Griban: 0000-0002-9049-1485 A,F

Olena T. Kuznietsova: 0000-0003-0536-421X $X^{B, D}$

Natalia A. Lyakhova: 0000-0003-0503-9935 E,F

Volodymyr M. Prystynskyi: 0000-0003-1681-3543 C

Dmytro G. Oleniev: 0000-0001-9685-725X ${ }^{D}$

Olena V. Otravenko: 0000-0001-8308-5895 ${ }^{A}$

Olena O. Pantus: 0000-0001-8146-6133 ${ }^{B, E}$

\section{Conflict of interest:}

The Authors declare no conflict of interest.

\section{CORRESPONDING AUTHOR Grygoriy P. Griban}

Zhytomyr Ivan Franko State University

40 Velyka Berdychivska St, 10002 Zhytomyr, Ukraine

tel: +380973341092

e- mail: gribang@ukr.net

Received: 20.11 .2020

Accepted: 07.03.2021

A - Work concept and design, B - Data collection and analysis, C - Responsibility for statistical analysis, D-Writing the article, $\mathbf{E}$-Critical review, $\mathbf{F}$ - Final approval of the article 